\title{
MATURAÇÃO in vitro DE OVÓCITOS DE GATA DOMÉSTICA (Felis catus)
}

\author{
(In vitro maturation of domestic cat (Felis catus) oocytes)
}

\author{
BAUDI, D.L.K. ${ }^{1}$; SPERCORSKI, K.M. ${ }^{2}$; MORAIS, R.N. ${ }^{3}$
}

'Médica Veterinária Autônoma, MSc; ${ }^{2}$ Médica Veterinária, Mestranda, UFPR - SCB - Departamento de Fisiologia; ${ }^{3}$ Médica Veterinária, MSc., PhD - UFPR - SCB - Departamento de Fisiologia.

\begin{abstract}
RESUMO - A preservação de material genético e a aplicação de biotécnicas reprodutivas têm sido sugeridas como método auxiliar na preservação de espécies. No presente estudo, ovócitos de gatas domésticas foram submetidos à maturação in vitro (MIV) com intuito de estabelecer um protocolo eficaz para a o uso posterior em felinos selvagens. Um total de 808 ovócitos (390 grau I e 418 grau II) foi coletado de ovários de 43 gatas, com uma média aproximada de 9 ovócitos de cada categoria por animal. Uma amostra de 156 ovócitos foi corada com fluoróforo específico para DNA, verificando o estágio meiótico. No total, $70 \%$ dos ovócitos atingiram Metáfase II, sendo considerados maduros. A taxa média de maturação dos ovócitos grau I $(74 \pm 3 \%)$ foi maior $(p<0,05)$ do que a dos grau II $(67 \pm 3)$. Conclui-se que os protocolos utilizados foram eficientes a a MIV de ovócitos de gata doméstica pode ser utilizada em nosso laboratório como referência para estudos com felinos selvagens.
\end{abstract}

Palavras-chave: maturação in vitro, ovócitos, felinos.

ABSTRACT - The establishment of genome resource banks and the application of assisted reproduction has been proposed as auxiliary tools for preserving endangered species. In this study domestic cat oocytes were matured in vitro (IVM) as a model for defining efficient protocols for wild felid species. A total of 808 oocytes (390 grade I and 418 grade II) were collected from 43 domestic cat ovaries, with a mean number of 9 oocytes, per category, per animal. To assess the meiotic cycle phase, 156 oocytes were stained with DNA specific marker. Overall, $70 \%$ of the oocytes were considered mature (Metáfase II). The mean maturation rate for oocytes grade I $(74 \pm 3 \%)$ were higher $(p<0.05)$ than that for oocytes grade II $(67 \pm 3)$. In conclusion, the described protocols were effective and domestic cat IVM can be used in our laboratory as a control for studies in wild felids.

Key-words: in vitro maturation, oocytes, feline.

\section{Introdução}

A busca de estratégias para a preservação de espécies em extinção tem impulsionado a comunidade científica a pesquisar alternativas para a preservação de material genético, com intuito de formação de bancos de genoma (WILDT e ROTH, 1997; SWANSON et al., 2003). Entre os diferentes tipos de tecidos e/ou células armazenados estão os gametas. Para os felinos selvagens Sul-Americanos, SWANSON et al. (2003) iniciaram um banco de genoma com amostras congeladas de sêmen e, posteriormente, produziram 76 embriões de jaguatirica e 52 embriões de gato-domato-pequeno que foram criopreservados para transferência posterior (SWANSON e BROWN, 2004).

Em paralelo aos bancos de genoma, está a aplicação das biotécnicas reprodutivas em felinos, incluindo a maturação e fecundação in vitro de ovócitos, a injeção espermática intracitoplasmática, a criopreservação de folículos, ovócitos, sêmen e embriões, com subseqüente transferência embrionária (GOODROWE, 1992; WILDT e ROTH, 1997; FARSTAD, 2000).

O presente estudo teve como objetivo maturar ovócitos provenientes de ovários de gatas domésticas com a finalidade de estabelecer um protocolo para a maturação in vitro de ovócitos de felinos em nosso laboratório e, assim, poder extrapolar a aplicação desta técnica para espécies de felinos selvagens.

\section{Materiais e Métodos}

Todos os reagentes, corantes, meios de cultivo e suplementos utilizados no presente estudo, exceto quando especificados, foram adquiridos da SigmaAldrich. Os meios de cultivo e soluções estoque foram preparados com água ultrapura (Sistema Puritech Permution, E.J. Krieger \& Cia Ltda), em vidraria estéril, sendo, a seguir, filtrados (Sterifil $47 \mathrm{~mm}, 22 \mathrm{~mm}$, Millipore) e transferidos em alíquotas, para frascos estéreis, sob capela de fluxo laminar.

Coleta dos ovócitos e maturação in vitro: Como fonte de ovócitos para os ensaios de maturação in vitro foram utilizados ovários de gatas domésticas adultas submetidas a ovariohisterectomia em clínicas

Correspondência para: MORAIS, R.N. - e-mail: moraisrn@ufpr.br - Telefone: (41) 3361-1719. 
veterinárias particulares e hospitais veterinários de Curitiba-PR. Os ovários foram transportados ao laboratório em solução salina tamponada contendo sulfato de estreptomicina $\left(0,05 \mathrm{~g} . \mathrm{L}^{-1}\right)$ e sal sódico de penicilina $\mathrm{G}\left(0,05 \mathrm{~g} \cdot \mathrm{L}^{-1}\right)$. Como recomendado, a coleta dos ovócitos foi feita dentro do intervalo máximo de seis horas após a cirurgia (COMIZZOLI, WILDT e PUKAZHENTHI, 2003; SPINDLER e WILDT, 1999b), sendo que $80 \%$ das coletas ocorreram em aproximadamente três horas após a intervenção cirúrgica.

Com exceção de pequenas modificações, a maturação in vitro dos ovócitos foi realizada conforme descrito por ROTH et al. (1995), SPINDLER e WILDT (1999b) e COMIZZOLI, WILDT e PUKAZHENTHI (2003). Resumidamente, os ovários foram colocados em placas de Petri de $35 \mathrm{~mm}$ contendo meio essencial mínimo de Eagle com sal de Hank e L-glutamina (HMEM), suplementado com albumina sérica bovina (4 g. $\left.\mathrm{L}^{-1}\right)$, ácido hidroxietil piperazina etanosulfônico (HEPES; $\left.6 \mathrm{~g} . \mathrm{L}^{-1}\right)$, sulfato de estreptomicina $\left(0,05 \mathrm{~g} . \mathrm{L}^{-1}\right)$ e sal sódico de penicilina $\mathrm{G}\left(0,05 \mathrm{~g} \cdot \mathrm{L}^{-1}\right)$. A seguir, foram submetidos a várias incisões com auxílio de uma lâmina de bisturi estéril para liberação dos complexos cúmulusovócitos (COCs). Sob ampliação de 32 vezes em estereomicroscópio e com auxílio de micropipeta de vidro (confeccionada a partir de um tubo capilar de microhematócrito aquecido em lamparina e esticado manualmente) os COCs foram selecionados e transferidos para outra placa contendo gotas de $100 \mathrm{ml}$ de meio HMEM.

Numa primeira etapa, foram selecionados os COCs com citoplasma escuro e homogêneo, sem vacúolos citoplasmáticos e totalmente envolvidos por no mínimo duas camadas de células cúmulus, denominados COCs grau I (WOOD e WILDT, 1997; COMIZZOLI, WILDT e PUKAZHENTHI, 2003). Os COCs grau I foram lavados três vezes, por meio de passagem em três gotas de meio HMEM, seguida de passagem em três gotas de meio de maturação (meio essencial mínimo de Eagle com sal de Earle e bicarbonato de sódio - EMEM, suplementado com L-glutamina $\left(0,292 \mathrm{~g} . \mathrm{L}^{-1}\right)$, albumina sérica bovina $\left(4 \mathrm{~g} . \mathrm{L}^{-1}\right)$, sulfato de estreptomicina $\left(0,05 \mathrm{~g} . \mathrm{L}^{-1}\right)$, sal sódico de penicilina $G\left(0,05 \mathrm{~g} \cdot \mathrm{L}^{-1}\right)$, piruvato $\left(11 \mathrm{~g} \cdot \mathrm{L}^{-1}\right)$, hormônio folículo estimulante (FSH, 2 mg.ml- ${ }^{-1}$; (Folltropin V, Vetrepharm Inc Canadá), hormônio luteinizante (LH, $2 \mathrm{mg}^{\mathrm{m}} \mathrm{m}^{-1}$; Lutropin V, Bioniche Animal Health Canada Inc) e b-Estradiol (2 mg. $\left.\mathrm{ml}^{-1}\right)$. Após isso, grupos de 10 a 20 COCs foram colocados em gotas de $100 \mathrm{ml}$ de meio de maturação cobertas com óleo mineral lavado, ambos previamente equilibrados em temperatura de $37^{\circ} \mathrm{C}$, atmosfera com $5 \%$ de $\mathrm{CO}_{2}$ em ar e máxima umidade, sendo incubados por 24 horas. Todo o processo entre incisão do ovário e colocação dos COCs grau I na incubadora levou entre 5 e 10 minutos.

Após esta etapa, foram coletados os COCs com citoplasma de coloração mais clara ou com presença de vacúolos, ou então que apresentavam falhas discretas nas camadas de células cúmulus, classificados como COCs grau II. Foi dispensado o mesmo tratamento aplicado aos COCs grau I quanto à lavagem e incubação.

Remoção das células do cúmulus: Após 24 horas de incubação, os COCs foram colocados em placa de Petri de $35 \mathrm{~mm}$ de diâmetro contendo meio HMEM com hialuronidase $(0,4 \%$; fórmula magistral), incubados a $37^{\circ} \mathrm{C}$ por 5 minutos (BYERS et al., 1994) e pipetados repetidas vezes para remover as células do cúmulus aderidas à zona pelúcida. Foram, a seguir, lavados em HMEM sem hialuronidase para remover os debris das células do cúmulus.

Avaliação da maturação in vitro: Após a remoção das células do cúmulus, os ovócitos foram fixados em $500 \mathrm{ml}$ de paraformaldeído (2\%) e Triton-X $(0,04 \%)$ por 45 minutos a $37^{\circ} \mathrm{C}$ (SPINDLER e WILDT, 1999b; RINGLEB, ROHLEDER e JEWGENOW, 2004). Na seqüência, foram corados com um fluoróforo específico para DNA (bisbenzimida $\mathrm{H}$

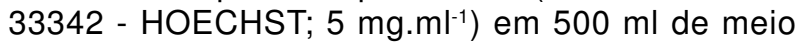
HMEM por 10 minutos a $37^{\circ} \mathrm{C}$ e montadas as lâminas para avaliação em microscópio de fluorescência. $O$ estágio do ciclo meiótico, foi visualizado e foram considerados maduros os ovócitos em metáfase II (SPINDLER e WILDT, 1999b).

Análise Estatística: Os dados foram submetidos a análise descritiva, calculando-se a média e erro padrão da média para as variáveis estudadas. Diferenças significativas entre os valores médios obtidos, de acordo com a categoria dos ovócitos (Grau I ou Grau II), foram detectadas por teste t de Student, para um alfa de $5 \%$.

\section{Resultados}

Um total de 86 ovários foi processado em todos os experimentos, dos quais foram coletados 390 ovócitos classificados como grau I $(39,2 \%)$ e 418 como grau II (42\%). Do total de 808 ovócitos submetidos à maturação in vitro, uma amostra de 19\% (156 ovócitos) foi utilizada para avaliação da taxa de maturação. Os demais ovócitos maturados não foram fixados por terem sido utilizados em experimento paralelo de avaliação de sêmen criopreservado (BAUDI, 2005). A taxa média geral de maturação foi de $70 \%$ e os valores médios, por categoria de ovócito, bem como o número médio de ovócitos por animal, são apresentados na TABELA 1. 
Maturação in vitro de ovócitos de gata doméstica (Felis catus)

TABELA 1 - NÚMERO DE OVÓCITOS COLETADOS DE OVÁRIOS DE GATAS DOMÉSTICAS ( $n=43$ ) E TAXA DE MATURAÇÃO MÉDIA ( \pm EPM) PARA OVÓCITOS GRAU I E II.

\begin{tabular}{lcc}
\hline & Ovócitos Grau I & Ovócitos Grau II \\
\hline № ovócitos coletados & $390(39 \%)$ & $418(42 \%)$ \\
№ ovócitos /gata & $9,1 \pm 1,4^{\mathrm{a}}$ & $9,7 \pm 1,4^{\mathrm{a}}$ \\
Percentual de maturação in vitro * & $74 \pm 3,4^{\mathrm{a}}$ & $67 \pm 3,3^{\mathrm{b}}$ \\
& $(73)$ & $(83)$ \\
\hline
\end{tabular}

$a, b$ - Letras diferentes indicam valores estatisticamente diferentes para $p<0,05$.

* Foram considerados maduros os ovócitos em metáfase II.

\section{Discussão}

Os felinos apresentam, em geral, ovulação reflexa e, 24 a 48 horas após o acasalamento, os ovócitos são liberados como ovócitos secundários em metáfase II (FARSTAD, 2000). Em condições de maturação in vitro, a maioria dos ovócitos atinge a metáfase II em 24 horas de incubação (WOLFE e WILDT, 1996). Entretanto, para se alcançar a maturação, os meios e condições de cultivo devem proteger os ovócitos de lesões oxidativas enquanto a adição de hormônios ao meio deve preservar a interação entre as células cúmulus e o ovócito, criando o nível de AMP cíclico intra-ovocitário ideal para a primeira divisão meiótica ocorrer (LUVONI e CHIGIONI, 2004).

Neste estudo, tanto o tempo de cultivo de 24 horas bem como os meios de cultivo utilizados permitiram obter taxas de maturação similares às descritas na literatura. $A$ taxa de maturação de $70 \%$ encontrada para todos os ovócitos avaliados, é um valor intermediário entre os valores encontrados por SPINDLER E WILDT (1999a,b) e por RINGLEB, ROHLEDER e JEWGENOW (2004), com variação entre $65 \%$ e $77,3 \%$. Percentuais inferiores $(44,68 \%)$ em gatas adultas, foram relatados por LOPES (2002) que também referiu uma taxa de coleta de 42,3 COCs por gata, um número considerado elevado por animal, incluindo possivelmente COCs em estágios menos desenvolvidos, o que pode comprometer a taxa média de maturação.

Segundo WOOD et al. (1997), o critério morfológico de seleção dos COCs promove a seleção de populações aparentemente homogêneas, porém que podem ter alta heterogeneidade funcional, podendo incluir folículos parcialmente atrésicos. Parte dos ovócitos Grau Il obtidos no presente estudo já poderiam estar nesta condição atrésica, o que implicaria em menores taxas de maturação em relação aos ovócitos Grau I, como observado. Outro fator evolvido nesta menor taxa de maturação pode ter sido o tempo despendido desde a remoção dos COCs até o início da incubação, o qual deve ser o menor possível, e neste estudo foi maior para os ovóçitos Grau II. Por estas razões, em estudos de fertilização in vitro, normalmente, apenas os ovócitos Grau I são selecionados (COMIZZOLI, WILDT e PUKAZHENTHI, 2003; RINGLEB, ROHLEDER e JEWGENOW, 2004).

Quanto ao número de COCs Grau I e II coletados por ovário, o número médio aqui encontrado está de acordo com os valores reportados, porém números expressivamente mais altos (LOPES, 2002) ou mais baixos (COMIZZOLI, WILDT e PUKAZHENTHI, 2003; SPINDLER e WILDT, 1999a) são também relatados. Diferenças no critério de seleção adotado é uma das principais justificativas para estas diferenças (FREISTEDT, STOJKOVIC e WOLF, 2001). Outros fatores implicados incluem a sazonalidade reprodutiva, idade e estado nutricional da fêmea. Como as gatas são poliéstricas sazonais, com atividade sexual durante os meses de dias longos, uma redução significativa no número e qualidade dos ovócitos coletados fora da estação reprodutiva foi observada por SPINDLER e WILDT (1999a). Do mesmo modo, em fêmeas prépúberes o número médio de ovócitos por ovário é menor (LOPES, 2002). Por outro lado, SWANSON et al. (2002), em estudo com fêmeas de jaguatirica e gatodo-mato-pequeno, observaram uma maior qualidade dos ovócitos obtidos por aspiração laparoscópica e também um maior índice de fertilização in vitro quando os animais eram mantidos sob dieta com suplementação vitamínica e mineral adequadas.

Apenas fêmeas adultas e saudáveis foram utilizadas no presente estudo, porém não foram obtidas informações precisas quanto à idade e estado nutricional dos animais. Além disso, a coleta dos ovócitos concentrou-se nos meses de primavera e verão, período favorável para a reprodução em felinos. Desse modo, apesar das muitas variáveis envolvidas, não houve alteração significativa nas taxas de maturação dos ovócitos das diferentes doadoras (dados não incluídos). É importante destacar que um número similar de ovócitos Grau I e II foram obtidos dos ovários de todas as doadoras e que, apesar da menor taxa de maturação, os ovócitos Grau II apresentaram competência funcional similar à dos ovócitos Grau II em testes in vitro de ligação espermática à zona pelúcida, tanto para sêmen de gato doméstico como de espécies selvagens (BAUDI, 2005).

\section{Conclusão}

Com base nas condições experimentais aqui descritas e nos resultados obtidos, conclui-se que os protocolos utilizados foram eficientes para a colheita, classificação e maturação in vitro de ovócitos de gatas domésticas. Fêmeas adultas, saudáveis e durante a estação reprodutiva podem fornecer cerca de 10 ovócitos de alta qualidade (Grau I) por animal, dos quais pelo menos $70 \%$ podem atingir o estágio de meiose II e serem utilizados em ensaios de fertilização in vitro. Um 
número similar de ovócitos Grau II pode ser obtido também de cada fêmea, os quais apresentam uma menor taxa de maturação, porém representam um material valioso para estudos da função espermática de felinos. Finalmente, ainda que os protocolos não possam vir a ser extrapolados diretamente para o uso em espécies selvagens, os dados obtidos neste experimento permitirão o uso da maturação in vitro de ovócitos de gata doméstica como prática de rotina em nosso laboratório, servindo como valores de referência e de controle de qualidade dos protocolos para os estudos com fêmeas selvagens.

\section{Agradecimentos}

Os autores agradecem ao Hospital Veterinário da PUC-PR, à Clínica Mania de Gato e à Clínica Veterinária Clinivet, bem como aos médicos veterinários de suas respectivas equipes técnicas, pelo fornecimento do material biológico utilizado neste estudo, e ao CNPq pela bolsa concedida.

\section{Referências}

BAUDI, D.L.K. Efeito de dois métodos de resfriamento sobre a função espermática in vitro de sêmen criopreservado de felinos (Leopardus tigrinus, Leopardus pardalis e Felis catus), avaliada através de ensaio competitivo de ligação em ovócitos de gata doméstica (Felis catus). Curitiba, 2005. 76f. Dissertação de Mestrado - UFPR.

BYERS, A.P.; DONOGHUE, A.M.; ROTH, T.L.; WILDT, D.E. Oocyte nuclear maturation at the time of oocyte aspiration is independent of in vitro fertilization potential in the domestic cat. The Journal of Experimental Zoology, v. 270, p. 399-404, 1994.

COMIZZOLI, P.; WILDT, D.E.; PUKAZHENTHI, B.S. Overcoming poor in vitro nuclear maturation and developmental competence of domestic cat oocytes during the non-breeding season. Reproduction, v. 126, p. 809$816,2003$.

FARSTAD, W. Current state in biotechnology in canine and feline reproduction. Animal Reproduction Science, v. $60-61$, p. $375-387,2000$.

FREISTEDT, P.; STOJKOVIC, M.; WOLF, E. Efficient in vitro production of cat embryos in modified synthetic oviduct fluid medium: effects of season and ovarian status. Biology of Reproduction, v. 65, p. 9-13, 2001.

GOODROWE, K.L. Feline reproduction and artificial breeding technologies. Animal Reproduction Science, v. 28 , p. $389-397,1992$

LOPES, M.D. Análise histológica, ultra-estrutural e avaliação da maturação nuclear de oócitos de gatas domésticas (Felis catus). Botucatu, 2002. $137 \mathrm{f}$. Tese (Livre Docência) - UNESP - Campus de Botucatu.
LUVONI, GC.; CHIGIONI, S. Cultural strategies for maturation of carnivores oocytes. In: INTERNATIONAL SYMPOSIUM ON CANINE AND FELINE REPRODUCTION, V, 2004, Embu das Artes, São Paulo. Abstracts Book: Basic and Applied Research on Domestic, Exotic and Endangered Carnivores. Embu das Artes, São Paulo, Brazil, p.30.

RINGLEB, J.; ROHLEDER, M.; JEWGENOW, K. Impact of feline zona pellucida glycoprotein B-derived synthetic peptides on in vitro fertilization of cat oocytes. Reproduction, v. 127, n. 2, p. 179-186, 2004.

ROTH, T.L.; SWANSON, W.F.; BLUMER, E.; WILDT, D.E. Enhancing zona penetration by spermatozoa from a teratospermic species, the cheetah (Acinonyx jubatus). The Journal of Experimental Zoology, v. 271, p. 323-330, 1995.

SPINDLER, R.E.; WILDT, D.E. Circannual variations in intraovarian oocyte but not epididymal sperm quality in the domestic cat. Biology of Reproduction, v. 61, p.188-194, 1999a.

SPINDLER, R.E.; WILDT, D.E. Relationship of substrate metabolism to cat oocyte maturation. Theriogenology, v. 51 , p. $295,1999 b$.

SWANSON, W.F.; BROWN, J.L. International training programs in reproductive sciences for conservation of Latin American felids. Animal Reproduction Science, v. 82-83, p. 21-24, 2004.

SWANSON, W.F.; JOHNSON, W.E.; CAMBRE, R.C.; CITINO, S.B.; QUIGLEY, K.B.; BROUSSET, D.; MORAIS, R.N.; MOREIRA, N.; O'BRIEN, S.J.; WILDT, D.E. Reproductive status of endemic felid species in Latin American zoos and implications for ex situ conservation. Zoo Biology, v. 22, p. 421-441, 2003.

SWANSON, W.F.; PAZ, R.C.R.; MORAIS, R.N.; GOMES, M.L.F.; MORAES, W.; ADANIA, C.H.; Influence of species and diet on efficiency of in vitro fertilization in two endangered Brazilian felids - the ocelot (Leopardus pardalis) and tigrina (Leopardus tigrinus), (Abstract). Theriogenology, v. 57, n. 1, p. 593, 2002.

WILDT, D. E.; ROTH, T. L. Assisted reproduction for managing and conserving threatened felids. International Zoo Yearbook, v. 35, p. 164-172, 1997.

WOLFE, B.A.; WILDT, D.E. Development to blatocysts from in vitro maturation and fertilization of domestic cat oocytes following prolonged cold storage ex situ. Journal of Reproduction and Fertility, v.106, n.1, p.135-141, 1996.

WOOD, T.C.; WILDT, D.E. Effect of the quality of the cumulusoocyte complex in the domestic cat on the ability of oocytes to mature, fertilize and develop into blastocysts in vitro. Journal of Reproduction and Fertility, v. 110, p. 355-360, 1997.

WOOD, T.C.; MONTALI, R.J.; WILDT, D.E. Follicle-oocyte atresia and temporal taphonomy in cold-stored domestic cat ovaries. Molecular Reproduction Development. v. 46, p. 190-200, 1997.

Recebido para publicação: $15 / 01 / 2006$ Aprovado: 